\title{
A linguistic history of iraqi arabic (mesopotamian arabic)
}

\author{
saja albuarabi \\ University of wisconsin - milwaukee \\ Email: saja@uwm.edu
}

\begin{abstract}
The objective of this work is to investigate the linguistic structure of Iraqi Arabic or what is known as Mesopotamian Arabic. The paper presents an overview of some of the fundamental analyses of Iraqi Arabic - Mesopotamian Arabic. This article is concentrated on the most important parts of the language which are the phonological, morphological, and syntactical features.

The paper not only examines the linguistic feature of Iraqi Arabic but it also, discusses how Iraqi Arabic dialect is different from Modern Standard Arabic with data that are not considered before and with certain new theoretical proposals.
\end{abstract}

The researcher analysis the three dialects, which are Baghdadi, Southern, and Maslawi dialect and provides an important data for each dialect. Unlike Modern Standard Arabic, Iraqi Arabic went through many changes.

Phonologically, Iraqi Arabic has more consonants than Modern Standard Arabic, and a few additional long vowels. Many sounds have been replaced with different sounds. In addition, the words in Iraqi Arabic does not end with vowels. Therefore, words end with consonants rather than vowels in Iraqi Arabic.

Morphologically, Iraqi Arabic is different from Modern Standard Arabic in the present progressive tense. In Iraqi Arabic, the tenses are formed by adding a prefix to the conjugated stem of the verb, which cannot be found in Modern Standard Arabic.

Syntactically, Iraqi Arabic differs from Modern Standard Arabic in two ways: first there is no case marking; Iraqi Arabic does not show overt cases as it is found in Modern Standard Arabic. Second, Iraqi Arabic lacks agreement. Iraqi Arabic does not always follow the structure of verb subject order as found in Modern Standard Arabic. The verb usually has full agreement with the subject in both orders, subject verb and verb subject. Finally, Iraqi Arabic has an interesting feature which is head movement that cannot be found in Modern Standard Arabic as Soltan argues. This is can be shown in the following example: [The student seems that he read the book.]

Among the other issues that the author discusses in this study are the history of Iraqi Arabic. In addition to the features of Iraqi Arabic and the effects of other languages, such as Turkish and Semitic languages on Iraqi dialects.

Keywords: Iraqi Arabic, Mesopotamian Arabic, MSA, syntax, agreement, voicing.

Date of Publication: 30.5.2018

DOI; 10.24297/jal.v9i2.7391

ISSN: 2348-3024

Volume: 9 Issue: 01

Journal: Journal of Advances In Linguistiics

Website: https://cirworld.com 
Website: https://cirworld.com

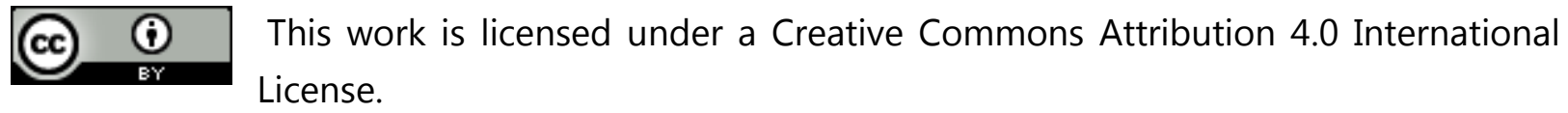

\section{Introduction}

Arabic language is an assembly of numerous variants, among which MSA has a unique position as the official written standard language of broadcast, art, music, literature and education throughout the Arab world. In Iraq, MSA can be used in media, meetings, and higher education institutes, while Iraqi Arabic can be found almost everywhere.

Arabic dialects differ in many dimensions, primarily geography and social class. Geo-linguistically, the Arab world can be divided in many different ways. The main Arabic dialects are Gulf Arabic, Iraqi Arabic, Levantine Arabic, Egyptian Arabic, and Maghrebi Arabic (Biadsy \& Hirschberg 2009). In this paper, I will focus only on the Iraqi Arabic.

The study tries to answer the following questions:

a. Why is MSA not used in Iraq anymore?

b. Can we consider the Maslawi dialect as the closest dialect to MSA? Why?

c. How do other languages affect the Iraqi Arabic?

to this problem and to answer the questions above, the study must go beyond MSA construction to see The first question we ask is why do Iraqi people do not use MSA nowadays? To provide a passable answer how the dialects (i.e., Iraqi Arabic) deal with these changes. The data that will be presented and discussed in section 2 suggests that the structure of MSA went through all of these changes because of the occupations in Iraq. This in turn raises the question of how far did the invasions affect Iraqi Arabic? Evidence from using examples of Iraqi Arabic provides syntactic and phonetic support for such problem. This issue plays an important role in the current discussion. The study will provide the evidence in section 3 and 4 to answer the aforementioned questions.

The paper contains seven sections. In section 2, I explain the background of the history of Mesopotamian Arabic, addressing the parts of the world in which this language has been found. Section 3 discusses the major differences between Iraqi Arabic and MSA. In section 4, I describe the Iraqi Arabic in the three different parts of Iraq (i.e. Baghdad, Musal, and the South). Moreover, I discuss which dialect is the closest dialect to the MSA, and explain why other dialects are not. Section 5 deals with the features of Iraqi Arabic. In section 6, I discuss the effects of other languages on Iraqi dialects, such as Turkish and Semitic languages. Finally, I conclude the paper with the results that answer the questions asked in the introduction. 


\section{The History of Iraqi Arabic/Mesopotamian Arabic}

Iraqi Arabic, or what is known as "Mesopotamian Arabic," is a dialect of Arabic and a subgroup of the Afro-Asiatic language family. Iraqi Arabic includes three distinguished sub-dialects within the country: Baghdadi, Southern, and Maslawi dialect (Abu-Haidar, 1989; Kessler, 2003).

Aramaic was the lingua franca in Iraq for many years, and, as may be expected, Iraqi Arabic demonstrates signs of an Aramaic substrate; the Gelet variety has kept the features of Babyloian Aramaic, until Iraq was affected by the Mongol occupation in 1258. In this era, many things changed, including the language (Kessler, 2003). Furthermore, due to Iraq's inherent multiculturalism, Iraqi Arabic exhibits extensive borrowing in its lexicon from Aramaic, Akkadian, Kurdish, and Turkish.

According to Al-Shabi (1965) Iraqi Arabic was affected by the Mongol occupation early in the second half of the seventh $(656 \mathrm{AH})$. In this era, many things had changed including the language. In his study, AlShabi points out that the present dialect of Iraqis is not much different from the dialect of the Iraqis in the ancient era of the Mogul. His study has been supported by Mutar (2009), who states that "There is only one Iraqi dialect for people who speak Arabic in Iraq, which is "Iraqi Arabic". It is wrong to return the original of Iraqi dialects to one of the Arabic community, such as the dialect of Bin Tamim, and consider its origins as Khalijī dialect (the dialect of the Gulf)." The author illustrates that in the history of Iraqi linguistics, Iraqi dialect is considered a pure Iraqi dialect, and its influence has increased to the Gulf countries because of the effects of marriage, culture relations and trade $(p, 9)$.

\section{The Differences between Iraqi Arabic and Modern Standard Arabic}

MSA is the official language of the Arab countries. According to Al-Bazi (2006) "Iraqi Arabic, unlike SA, which is not a native language of any Arab countries but is the language of education across the Arab world, is the spoken language of everyday activities at home, at work, on the street, and on social occasions" (p. 22). Iraqi Arabic is spoken in Iraq as well as in some areas of Syria, Southeastern Turkey, and part of Iran.

Biadsy and Hirschberg (2009) indicate that MSA is the language that is used officially in the broadcast and institutes in the Arab world. The syntactical, morphological and phonological features of MSA are based on Classical Arabic, which is the language of the Qur'an (Islam's Holy Book).

The Arabic dialects, such as Iraqi Arabic, in contrast, are the true native language forms. The dialects are generally restricted in use to informal daily communication. They are not taught in schools or even standardized. Iraqi Arabic differs from MSA phonologically, morphologically, and syntactically.

\subsection{Phonological Differences}

Phonologically, Iraqi Arabic is different from MSA. Al- Bazi (2006) states that the Iraqi dialect has 3 consonants more than the MSA, and 3 additional long vowels compared to the standard ones (p. 23).

${ }^{1}$ Mesopotamia was first home to the villages in the Neolithic period of around 6,000 BC. Permanent mudbrick residential structures were being constructed before the Ubaid period at southern sites such as Tell el-Oueili, as well as Ur, Eridu, Telloh, and Ubaid. 


\subsubsection{Consonants}

Iraqi dialects have these additional consonants voiced $/ \mathrm{g} /$, voiceless $/ \mathrm{ch} /$, and voiceless $/ \mathrm{p} / \mathrm{which}$ cannot be found in MSA. The first consonant $/ \mathrm{g} /$ can be seen in the following example:

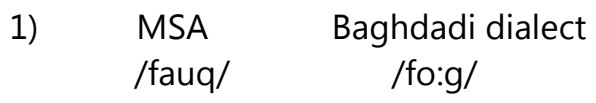

(over, on) (over, on)

It is important to understand that there is an MSA sound / $\mathrm{q} /$ which is different from $/ \mathrm{k} /$. This / $\mathrm{q} /$ is a post-velar voiceless stop represented by an Arabic letter, different from the sound $/ \mathrm{g} /$, a velar voiced stop represented by this dialectal 'gaaf' letter. According to the author, Baghdadi dialect uses a diaphone $\mathrm{g} /$ to articulate $/ \mathrm{q} /$ in most of the words of the language without changing the meaning.

The second consonant is /ch/. The author illustrates that this sound restricts itself to the southern and Baghdadi dialects. It is similar to the English voiceless affricate sound (a combination of the stop / $t$ / and fricative /sh/). This sound /ch/ can be found in 1) loan words, such as "chaakuuch" (hammer), and also in 2) an allophone for the / $\mathrm{k} /$ sound in certain words, such as "chaan" (he was).

The last consonant is /p/. Al-Bazi (2006) states that the Iraqi dialects have the voiceless and aspirated stop labial /p/ at the beginning, middle, and end of words which is different from the MSA. This is because these words are borrowed words taken from other languages, such as /parda/ curtain (p. 32).

\subsubsection{Vowels}

Alkalasi (2007) illustrates that the MSA has only 3 vowels (aa, oo, uu) while the Iraqi dialects have five long vowels (aa, ee, ii, oo, uu), and four short vowels $(\mathrm{a}, \mathrm{i}, \mathrm{o}, \mathrm{u})$. "There are two additional vowels in the Iraqi dialects compared with those of classical Arabic. They are longer than the classic sounds, though they have the same written form" (Al- Bazi, 2006, p. 34). Unlike MSA, the Iraqi dialects do not add a vowel to the end of words, and they end with consonants rather than vowels. It is remarkable to say that the Iraqi dialect imperative verbs, unlike the Standard Arab, do not drop the long vowels in orders, such as 'guum' which means 'stand up, get up'.

\subsection{Morphological Differences}

Morphologically, Iraqi Arabic is different from SA in the present progressive tense. In Iraqi Arabic, the prefix [da-] is added to the conjugated stem of the verb to form the present progressive tense, which cannot be found in MSA, as shown in (2).

2) ?an-a Pdrus-u Pal?an

I am studing-1S now

SV Order-Modern Standard Arabic

"I am studying now."

3) ?ani da-?drus.

I am studying

"I am studying."

SV Order-Iraqi Arabic

Al-Bazi (2006) states that the prefix [da-] is borrowed and adapted from Persian into the early Abbasid-era Baghdadi dialect. For example, "I am saying" is pronounced "Ani da-agool," and "I am laughing" is "Ani 
da-adhHak." The author indicates that the Iraqi Arabic uses a masculine plural verb form for both masculine and feminine plurals. In Iraqi Arabic, the vowel /a/ in the first syllable of the verb changes into / $\mathrm{i} /$ in the masculine plural. In MSA, /-u:na/ at the end of the verbs refers to the plural masculine (p. 43).

\subsection{Syntactical Differences}

Syntactically, Iraqi Arabic differs from MSA in case marking; Iraqi Arabic does not end words with vowels, and it does not show overt cases. Therefore, words end with consonants rather than vowels, as illustrated in the following example:

4) qara-tu ?al-kitaab-a read-1S the-book-ACC VS Order-Standard Arabic

"I read the book."

5) qri:t ?al-kitaab

read the

book VS Order-Iraqi Arabic

"I read the book."

\subsection{Agreement Differences}

3.5

3.6 Arabic is a language that has a complicated agreement structure. Subject-verb agreement can be affected by the word order. The forms of agreement in Arabic differ from other patterns of agreement in other languages. As a result, the attested agreement patterns challenge existing syntactic analyses of agreement.

Generally speaking, the agreement in MSA is as follow ${ }^{2}$ : in a Verb Subject (VS) structure as in (6), the verb agrees with the subject in gender and person only, while in Subject Verb (SV) order, the verb agrees in person, number, and gender with the subject, as in (7).

6) VS order-Partial agreement

a) daras-a ?al-tulab-u studied-3MS the-students-NOM

"The students studied the lesson."

b) Daras-at ?al-talibat-u studied-3FS the-students-NOM

"The students studied the lesson."

7) SV order-Full agreement

a) Tal-tulab-u daras-u Pal-darsa the-students-NOM studied-3MP the-lesson-ACC

"The students studied the lesson."

b) Zal-talibat-u daras-na 7al-darsa the-students-NOM studied-3FP the-lesson-ACC

2 The full agreement in SV and the partial agreement in VS have been one of the most recognized topics in numerous studies. I will not dwell on this issue here (see Mohammed (1990) and Soltan (2007) for further discussion). 
"The students studied the lesson."

In contrast, agreement in Iraqi Arabic, like other dialects, does not always follow the structure of VS order in MSA. The verb usually has full agreement with the subject in both orders, Subject Verb (SV) and VS, as example (8) shows.

8) Standard Arabic

a) naam-a Pal-atfal-uu slept-3MS the-children-NOM

"The children slept."

VS Order-Partial Agreement

b) Pal-atfal-uu naam-uu the children-NOM slept-3MP

"The children slept."

9) Iraqi Arabic

a) naam-wo (*naam-a) ?al-atfal slept-3MP thechildrenVS Order-Full Agreement "The children slept."

b) Tal-awlad naam-wo the children slept-3MP SV Order-Full Agreement

"The children slept."

However, there are some exceptions where the verb agrees partially with the subject in

VS order, as illustrated below.

10) Standard Arabic

a) qara-a ?al-tulab-uu ?al-kitab-a read-3MS the-students-NOM the-book ACC "The students read the book."

VS Order-Partial Agreement

b) Tal-tulab-uu qara-uu ?al-kitab-a the-students-NOM read-3MP the-book ACC "The students read the book."

SV Order-Full Agreement

11) Iraqi Arabic

a) qara Pal-tulab ?al-kitab read-3MS the-students the-book "The student read the book."

VS Order-Partial Agreement

b) Tal-tulab qara-wo ?al-kitab the-students read-3MP the-book "The student read the book."

SV Order-Full Agreement

In this section, I have discussed some important issues regarding Iraqi Arabic. I have presented the most important differences between Iraqi Arabic and MSA. The main purpose of this section is to review the differences between the two languages. From the discussion above, it is clear that Iraqi Arabic does not have overt cases, and the verb shows full agreement instead of partial agreement in the VS structures. In the next section, I discuss the three sub-dialects of Iraqi Arabic and demonstrate which dialect is the closest dialect to MSA. 


\section{Iraqi Dialects}

The Iraqi dialect includes three distinguished sub-dialects within the country. Muter (2009) explains that the Iraqi dialect tends to be rural when one moves from Mosul to the South.

\subsection{Dialect of Baghdad}

Baghdadi dialect is the famous dialect in Iraq. It can be found in the middle of Iraq, in Baghdad, the Capital, and in the areas near to it. This dialect is characterized by its simplicity and clarity of speech, which make it closer to Iraqi dialects eloquent. It also tends to amplify the sounds, such as /o/ sound, as in (shino/what), which other dilaects do not have. Furthermore, it does not turn the sound $/ \mathrm{k} / \mathrm{to} / \mathrm{g} /$, as the dialect of the south does. As can be shown in the following example:

$\begin{array}{lll}- & \text { kal } & \text { "say" } \\ - & \text { gal } & \text { "say" }\end{array}$

Baghdadi dialect

Southern dilacts

It is worth mentioning that the characteristic Baghdadi dialect was not used by a lot of people who live in that area, while people like Jews and Christians kept using the dialect because they did not mix or marry with other people who came from different places (Muter, 2009, p. 10).

\subsection{Dialect of the South}

This dialect can be found in the south, such as in Basrah, Thi-Qar, Babylon, and Najaf. It is also known as (Sharkawiya) which means the dialect of East Iraq. This dialect is characterized by reduction and switching /k/ to /g/ or /ch/ sound in many cases. Muter (2009) explains that most of the farmers in Basrah province tend to turn the sound $/ \mathrm{k} /$ to $/ \mathrm{dh} /$ because it is hard for them to pronounce the $/ \mathrm{k} / \mathrm{sound}$. Also, this dialect is famous for using the word "cha" which means "so" in MSA.

Kessler (2003) states that the origin of the word "cha" is the Aramaic word "Ka" which gives the same meaning and is used in the same way, especially before verbs. This word is still used in Aramaic poems. People who speak this dialect tend to speak it fast, and for that reason sometimes it is hard to understand some of the words used by them, especially in the rural locales.

\subsection{Dialect of the North}

This dialect can be found in Musol and some areas around it. Muter (2009) presents that this dialect keeps the $/ \mathrm{k} /$ sound and does not turn it to other sounds as we have seen in the previous dialects. What characterizes this dialect is turning the / $\mathrm{r} /$ sound to /gh/ as in this word ' $\mathrm{ghah}$ ' originally 'rah' which means 'went'. The dialect of Alanbar is a mix between the Baghdadi dialect and Bedouin (rural), which has plenty of the old Bedouin vocabulary. The dialect of Alanbar is clear and light.

What we could conclude from these three dialects is that the Maslawi dialect (dialect of the North) can be considered as the nearest dialect to the MSA as it keeps most of the alphabet letters in everyday conversation.

\section{Iraqi Arabic Features}

A lot of studies have been done about the Iraqi Arabic characteristics. According to Al-Bazi (2006), Iraqi Arabic has some features that are different from MSA, such as in the case of assimilation and voicing. In 
Iraqi Arabic, one voiceless sound affects the other because the adjacent one is voiced (p. 14). There are many examples in MSA and in Iraqi Arabic that show this phenomenon: the sound /j/ changes into /ch/ when we pronounce the words together quickly as shown in this example:

12) Modern Standard Arabic

?iSTadamat Sayaarati bi-I Haa?iT

hit my car with- the wall

"My car hit the wall."

13) Iraqi Dialect

STidmatil sayaara $\mathrm{w}$ ?aani inSidamit

hit the car and I shocked

"My car collided and I was shocked."

A voiceless sound can be affected by voicing surrounding consonants. If the effect of the sound goes backward, the assimilation is called regressive. In standard we say /s/ hard, but in Iraqi dialect we say /z/ soft because /ii, gh/ are all voiced and cause the /s/ to change into a voiced/z/. The movement of the effect is going backward; therefore, the assimilation is regressive as shown in this example:

14) /SalaTa/ MSA /zalaTa/ Iraqi Arabic

/s/ changes into / $\mathrm{z} /$ in the word above which means (salad)

Another feature of Iraqi Arabic is using the word (illy/that, this, or those) which cannot be found in MSA. Furthermore, some words of Iraqi Arabic have particular letters that cannot be found in MSA, such as /q/ as in 'qal' which means 'he said', and /ch/ as in 'kotabch' which means 'your book/f' (Mutar, 2009, p. 9-10).

\section{The Effect of Other Languages on Iraqi Arabic}

The conquest of the Mongols and Turkmens on Iraq had major effects on the Iraqi Arabic. Because of its location Iraq became the central of the Islamic Golden Age during the Iron Age and Classical Antiquity. It fell under Ottoman rule in addition to Sumerian, Babylonain, and akkedian.

\subsection{Turkish Language}

Iraqi went through two periods because of the Ottoman Empire occupation in (1534-1704 \& 1831-1920). The Iraqi Arabic had been affected by the Ottoman Empire, mainly in Musol. The city of Musol was under the Ottoman Turkish occupation for a long time. The Ottoman Turkish occupation impacted the people of Musol in all aspects. The Musol vernacular has been affected by the Turkish language. People there had to learn the Turkish language - even the lessons in the schools were taught with Turkish language.

It can be clearly seen that some of the people in Musol use some words of Turkish language, such as 'barda' which means 'starah' in MSA and 'curtain' in English. Another reason that Musol's people have been affected by the Turkish language is because of trade and marriage (Mutar, 2009).

For this reason, Turkish language played a central role effecting the Iraqi Arabic and changed its form syntactically, and phonologically. 


\subsection{Semitic Language}

Salah (1993) states that the Semitic languages emerged in the late eighteenth century in Germany. Scientists divided the Semitic languages according to the northeast (Mesopotamia), northwest (Syria and Palestine), and southwest (Arabia and Ethiopia). The family includes the Semitic languages of the northeast in various stages of Akkadian, Assyrian, and Alamoria old. The Semitic languages in the northwest consist of Canaanite, its subsidiaries and Almaabih Hebrew, Phoenician, Ugaritic, and also includes Alamoria (Canaanite East) and Aramaic. The Semitic languages in the southwest consist of the south Arabic, such as Sboah and Himyarite. (p. 5-6).

The majority of Iraqi people still use some of the words that are from Semitic languages, such as the famous word 'aku' in Iraqi dialect, which replces the word 'aka' in the Semitic language, which means 'exists.' It seems that the root of the verb 'anty,' 'Antini' in Iraqi Arabic, is closer to Aramaic than MSA 'aatini,' which means 'give me' (Al-Shebi , 1965).

\section{Conclusion}

The purpose of this paper has been to investigate Iraqi Arabic \Mesopotamian. The study tries to reach possible answers for the questions that have been raised through this work. The results of the previous sections are as follows: MSA is not the language that is used by Iraqi people. Iraqi Arabic, on the other, is the language which is used in everyday conversation. A lot of sounds, letters and words have been insert from other languages, such as Turkish and Semitic to Iraqi Arabic.

In section 1, I presented a brief introduction about MSA and Iraqi Arabic. In order to explore the structure of Iraqi Arabic, a number of questions were raised that other studies did not discuss. Section 1 can be considered as a short introduction to the study.

In section 2, I have presented the history of Iraqi Arabic\Mesopotamian Arabic. Also, I have mentioned how Iraqi Arabic is different from Modern Standard Arabic. I explained when MSA is mainly used and how it is morphologically and phonologically based on Classical Arabic. The study demonstrated that MSA is not the native language of Iraq, but it is the language of education across the country. It can be used formally in schools, courts, and newspapers. Iraqi Arabic, in contrast, is the native language that is used by many Iraqi."It is generally restricted in use to informal daily communication. It is not taught in schools or even standardized, although there is a rich popular dialect culture of folktales, songs, movies, and TV shows" (Habash, 2010).

In section 3, I have shown the differences between Iraqi Arabic and MSA phonologically, morphologically, and syntactically. "MSA has its own phonology, grammar, syntax system, and rich lexicon of classical literature with its own social discourse" (Alkalesi, 2007, p. 22). Phonologically, Iraqi Arabic has two additional vowels compared to the vowels of MSA. What separates Iraqi Arabic from MSA is the fact that it ends with consonants rather than vowels.

Morphologically, Iraqi Arabic, adds the prefix [da-] to the verb to form the present progressive. This structure cannot be found in MSA. Finally, the section explained that Iraqi Arabic does not show cases marking on the verbs.

Section 4 presented the three dialects and explained which dialect is the closest dialect to MSA. The section illustrated that the Maslawi dialect (dialect of the North) can be considered as the closest dialect to the MSA, as it keeps most of the alphabet letters and MSA structure in the daily communication. 
In section 5, I showed the features of Iraqi Arabic regarding assimilation and how Iraqi Arabic has extra letters and words that cannot be found in MSA.

Finally, the paper concluded that Turkish and Semitic languages have had a great influence on Iraqi Arabic as many words and structures from both languages are still used till now.

\section{References}

1. Abu-Haidar, F. (1989). Are Iraqi women more prestige conscious than men? Sex differentiation

2. in Baghdadi Arabic. Language in Society, 18(4), 471-481.

3. Alkalesi, Y. M. (2007). Modern Iraqi Arabic. Washington, D.C

4. Al- Bazi, M. (2006). Iraqi dialect versus standard Arabic. California. USA

5. Al-Shebi, M. R. (1965). The origins of the words in Iraqi dialect. Paper presented at the Cairo

6. Conference.

7. Biadsy, F., \& Hirschberg, J. (2009). Spoken Arabic dialect identification using

8. phonotactic modeling. Journal of Association for Computational Linguistics. 53-61

9. Habash, N. (2010). Introduction to Arabic Natural Language Processing. San Rafael, California

10. USA

11. Kessler, Ch. Ml. (2003). Aramaic ?k?, lyk? and Iraqi Arabic ?aku, maku: the

12. Mesopotamian particles of existence. Journal of the American Oriental Society 123(3), 641-46.

13. Mutar, S. (2009). Mesopotamian, encyclopedia of Iraqi languages. Beirut. Lebanon

14. Saleh, Th. (1993). The effect of Semitic languages in modern Iraqi Arabic. Journal of Life of

15. London 18, 1-8.

16. Mohammed, M. A. (1990). The problem of subject-verb agreement in Arabic: Toward a

17. solution, in Mushira Eid (ed.). Perspectives on Arabic Linguistics I: Papers from the First Annual Symposium on Arabic Linguistics. John Benjamins Publishing Company, Amsterdam. 95-125. Linguistics Theory, 36, 97-126. 